This PDF is a selection from a published volume from the National Bureau of Economic Research

Volume Title: Frontiers in Health Policy Research, Volume 6

Volume Author/Editor: David M. Cutler and Alan M. Garber, editors

Volume Publisher: MIT Press

Volume ISBN: 0-262-03309-7

Volume URL: http://www.nber.org/books/cutl03-1

Conference Date: May 29, 2002

Publication Date: January 2003

Title: Demand Effects of Recent Changes in Prescription Drug Promotion

Author: Meredith B. Rosenthal, Ernst R. Berndt, Julie M. Donohue, Arnold M. Epstein, Richard G. Frank

URL: http://www.nber.org/chapters/c9862 


\title{
Demand Effects of Recent Changes in Prescription Drug Promotion
}

\author{
Meredith B. Rosenthal, Harvard School of Public Health
}

Ernst R. Berndt, Massachusetts Institute of Technology and NBER

Julie M. Donohue, Harvard Medical School

Arnold M. Epstein, Harvard School of Public Health

Richard G. Frank, Harvard Medical School and NBER

\section{Executive Summary}

The release of clarified Food and Drug Administration (FDA) guidelines and independent changes in consumer behavior provide an opportunity to study the effects of direct-to-consumer advertising (DTCA) in the prescription drug market alongside the effects of various physician-oriented promotions. We examine the effects of DTCA and detailing for brands in five therapeutic classes of drugs, using monthly aggregate U.S. data from August 1996 through December 1999. In terms of impact of DTCA on demand, we provide evidence on two issues: (1) do increases in DTCA increase the market size of an entire therapeutic class? and (2) does DTCA increase within-class market share of advertised drugs? Our findings suggest that, for these classes of drugs, DTCA has been effective primarily through increasing the size of the entire class. Overall, we estimate that 13 to 22 percent of the recent growth in prescription drug spending is attributable to the effects of DTCA.

Advertisements contain the only truth to be relied on in a newspaper.

Thomas Jefferson ${ }^{1}$

Advertising is a racket ... its constructive contribution to humanity is exactly minus zero.

F. Scott Fitzgerald ${ }^{1}$

I think I was wrong.... On the whole, I think there is a lot of educational benefit [to direct to consumer prescription drug advertising].

David A. Kessler, M.D., former FDA Commissioner ${ }^{2}$ 
Since 1994, total spending on consumer-directed promotion for prescription drugs has grown nearly tenfold (Henry J. Kaiser Family Foundation 2000). Consumers and their physicians report that prescription drug advertisements are increasingly influential. In surveys of consumers, the share of people reporting that they have seen an advertisement on television or heard an advertisement on the radio for a prescription drug more than doubled between 1993 and 2000, reaching 81 percent by 2002 (Alperstein and Peyrot 1993, Newshour with Jim Lehrer/ Henry J. Kaiser Family Foundation/Harvard School of Public Health 2000, Aikin 2002). Some estimates indicate that as many as 25 percent of Americans have asked their doctors about a medication as a result of seeing an advertisement (Prevention Magazine 2001). Similarly, many physicians report that their patients have asked them about drugs as a direct consequence of consumer advertising (Borzo 1997, KaufmanSherr and Hoffman 1997).

The rise of direct-to-consumer advertising (DTCA) of prescription drugs represents a departure from the industry's historical concentration on promotion to physicians, hospitals, and other health care organizations. ${ }^{3}$ This phenomenon is highly targeted toward a minority of products. In one recent study of 391 major branded drugs in 1999, only 18 percent had positive DTCA expenditures, whereas 95 percent of brands sent "detailers" to visit physicians' offices (Neslin 2001). Traditional physician-oriented forms of promotion remain important. Even among those products that employ DTCA, professional promotion continues to command a larger share of marketing budgets (table 1.1).

The change in marketing mix by pharmaceutical manufacturers is likely a response to recent changes in market and regulatory conditions. ${ }^{4}$ Consumers are increasingly seeking active participation in their own health care, aided in part by the wealth of information available on the Internet. At the same time, physicians may have less discretion over choice of brand-name drugs than they once did as a result of direct and indirect constraints placed on their prescribing behavior by managed care. In addition, in 1997, the FDA released explicit tentative guidelines (finalized in 1999) regarding advertising to consumers via electronic media that may have facilitated more widespread use of this promotional strategy. In particular, the new FDA guidelines clarified the requirements for adequate disclosure of information concerning indications, and risks and effects of a drug, thus removing a major barrier to television and radio advertising (Rosenthal et al. 2002). 
The release of clarified FDA guidelines and independent changes in consumer behavior provide an opportunity to study the effects of DTCA in the prescription drug market as well as the effects of various physician-oriented promotions. In this paper, we examine the effects of two types of promotional spending for brands in five therapeutic classes of drugs, and we use monthly aggregate U.S. data from August 1996 through December 1999. Specifically, we provide evidence on two issues: (1) do increases in DTCA increase the market size of an entire therapeutic class? and (2) does relative DTCA within a given therapeutic class affect market shares within that therapeutic class? In both cases, we examine the effects relative to traditional physician-oriented promotional efforts.

\section{Review of Related Literature}

Our research builds on and relates to several other studies. Early economic studies of physician-oriented marketing of prescription drugs by Bond and Lean (1977), Hurwitz and Caves (1988), Leffler (1981), and Vernon (1981) considered evidence regarding whether this marketing was more "persuasive" than "informative," although the distinction between the two was ambiguous. This distinction reflects an earlier, more general literature that viewed advertising alternatively as changing consumers' preferences (Kaldor 1950), creating or exaggerating product differentiation and thereby increasing barriers to entry (Bain 1956), or providing information about a product's characteristics and its price (Stigler 1961). A common finding from the empirical literature was that professional promotion of prescription drugs increased entry costs and decreased price competition by increasing perceived product differentiation. A related medical study on physician detailing by Avorn, Chen and Hartley (1982) advocated that counterdetailing be utilized to offset the unbalanced information provided by prescription drug detailers. ${ }^{5}$

More recent research by King (2000) on anti-ulcer medications finds that a brand's own marketing reduces (in absolute value) a brand's own price-elasticities of demand, but that total industry marketing (i.e. the sum of marketing expenditures for each brand in the class) reduces the extent of product differentiation. Berndt et al. (1997) distinguish between "industry expanding" and "rivalrous" marketing efforts, and find that, for anti-ulcer medications, both medical journal 


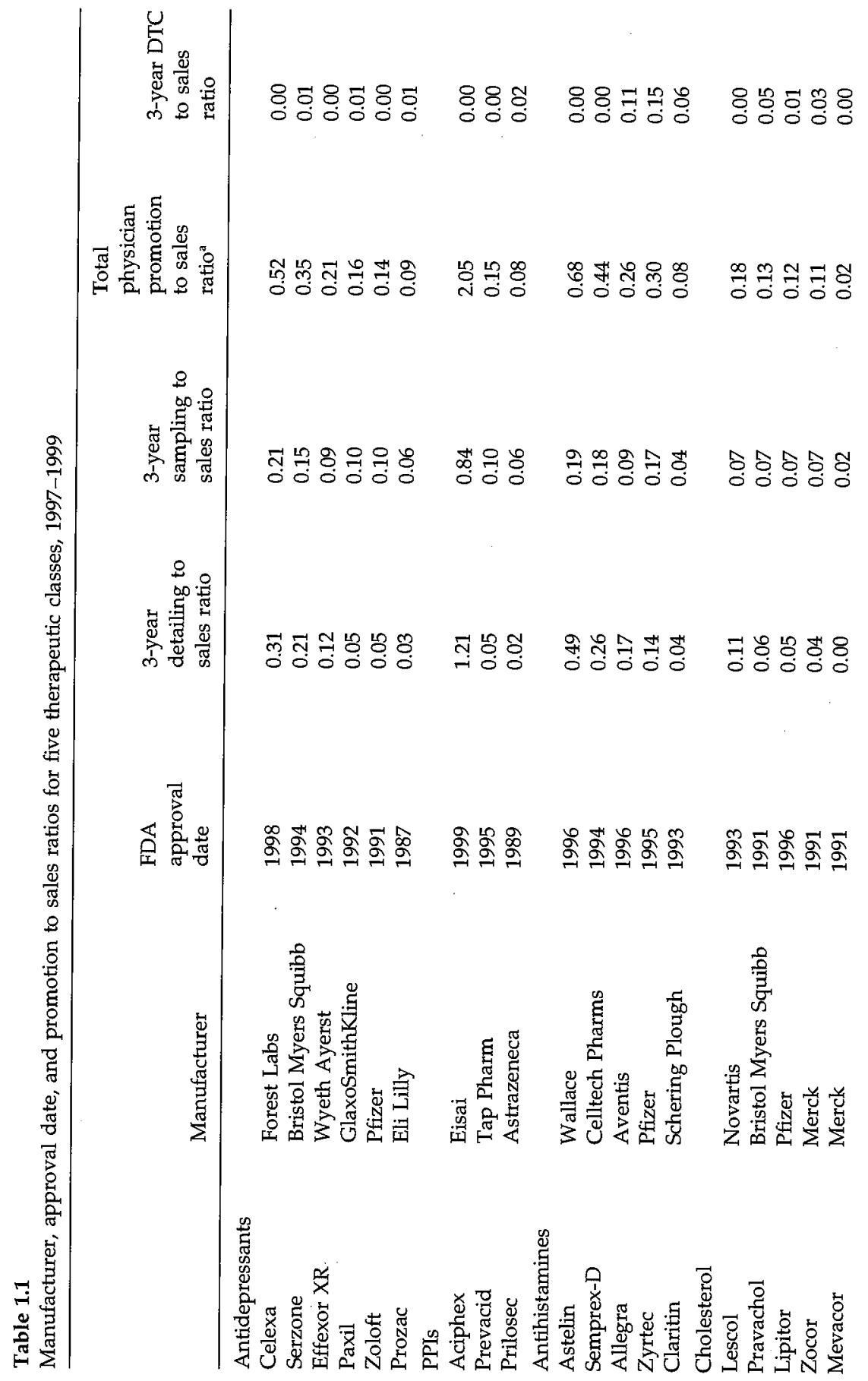




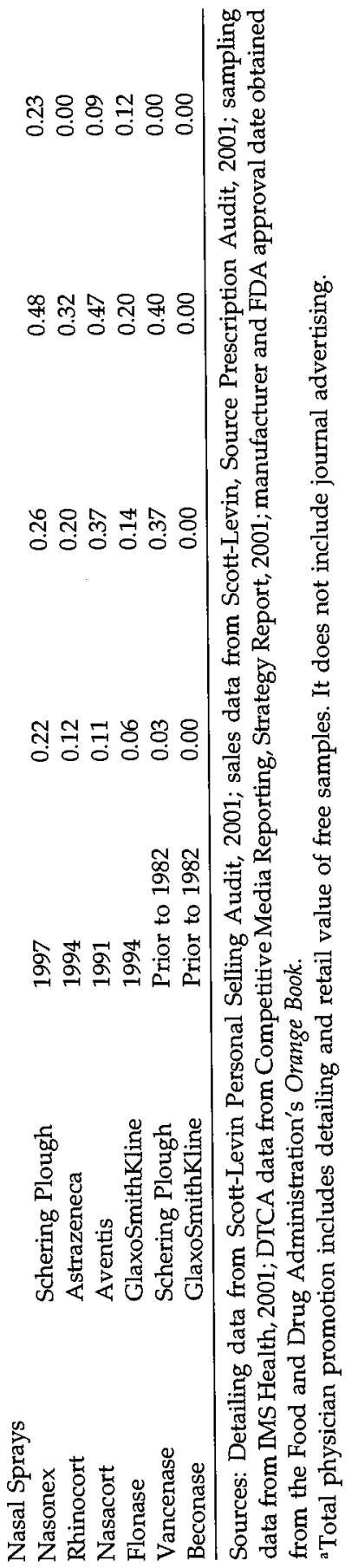


and physician detailing marketing stocks positively affect own-brand sales. They also report that the impact of total class marketing efforts on total class sales is positive, and generally (but not always) declines with the number of products on the market. Rizzo (1999) reports that for antihypertensive drugs, both stocks and flows of detailing expenditures decrease the price elasticity through the development of greater brand loyalty.

Using a proprietary data set from a pharmaceutical manufacturer that incorporates physician-specific marketing measures for one of its brands, Manchanda, Chintagunta and Gertzis (2000) find that detailing has a significant positive impact on the number of prescriptions written for that drug by the physician; that this marginal impact increases when free product samples are also provided to the physician; and that, for the majority of physicians in their sample, diminishing (though still positive) returns to detailing had already set in. Gonul et al. (2001) report similar diminishing returns to physician detailing, but find that detailing and free samples increase price sensitivity, where price is measured as the average retail price for the drug.

The empirical studies cited above focused on physician detailing and in some cases on medical journal advertising, but did not examine DTCA. ${ }^{6}$ Unlike physician-oriented promotions, to the extent DTCA might raise awareness among previously untreated consumers of the existence of potentially effective treatments, DTCA could bring more patients into physician offices. Whether the effect of such increased "physician office foot traffic" is greater on overall therapeutic class sales, or on the share of sales for the specific brand named in the advertisement, is unclear a priori and is an empirical question addressed in this study.

Prior to 1997, DTCA was permitted if a medical condition was mentioned but the brand was not; or if the brand was mentioned, no mention was made of the medical condition for which it was intended, and instead the ad encouraged the individual to see her or his physician regarding the brand. Berndt et al. (1995) obtained advertising agency DTCA data for branded anti-ulcer ( $\mathrm{H}_{2}$-antagonist) prescription drugs through May 1994, along with detailing and medical journal advertising data from other sources. For the entire $\mathrm{H}_{2}$ therapeutic class, advertising demand elasticities were 0.55 for detailing, 0.20 for medical journal advertising, and 0.01 for this type of DTCA; the sum of these elasticities is 0.76 , suggesting decreasing returns to scale for overall advertising. Within this therapeutic class, although a brand's own de- 
tailing and medical journal advertising stocks positively affected market shares, this was not the case for DTCA.

Two recent studies of DTCA by Wosinska (2001) and Ling, Berndt, and Kyle (2002) incorporate data after the FDA's 1997 clarification of DTCA guidelines. Using 1996-1999 prescription drug claims data for 4,728 patients who filled a total of 11,529 new prescriptions for cholesterol-reducing drugs in the Blue Shield of California medical plans, along with national data on physician detailing, samples, and DTCA, Wosinska finds that DTCA positively affects total therapeutic class sales, but affects an individual brand positively only if that brand has a preferred status on the third-party payer's formulary.

Unlike the cholesterol-reducing drugs, the $\mathrm{H}_{2}$-antagonist drugs are sold in prescription ( $R x)$ form and, since 1995-1996, also as over-thecounter (OTC) drugs. Both OTC and Rx versions of these brands have utilized DTCA, and thus various spillovers between $R x$ and OTC DTCA can be assessed, both between and within brands. Ling, Berndt, and Kyle find that DTCA marketing of OTC brands has no spillover to the same brand in the Rx market. Within the Rx market, own-brand physician-oriented detailing and medical journal advertising efforts have positive and long-lived effects on own Rx market share, while DTCA of the Rx brand has no significant impact on own Rx market share. Within the OTC market, not only are own-brand effects of DTCA on the OTC brand significantly positive and long-lived, but physicianoriented Rx marketing efforts have positive own-brand spillovers to the OTC share. DTCA efforts for $R \times$ brands have no significant impact on same-brand OTC shares.

\section{Theoretical Considerations}

The codfish lays ten thousand eggs,

The homely hen lays one.

The codfish never cackles

To tell you what she's done.

And so we scorn the codfish,

While the humble hen we prize,

Which only goes to show you

That it pays to advertise. ${ }^{1}$

The theoretical foundations underlying the economics of advertising rely in large part on Dorfman and Steiner (1954), who showed that for a profit-maximizing monopolist facing a downward-sloping 
linear demand curve, the optimal advertising expenditure to dollar sales ratio equaled the ratio of two elasticities: $\varepsilon_{Q A}$-the elasticity of quantity demanded with respect to advertising efforts, and $\varepsilon_{Q A}$-the elasticity of quantity demanded with respect to price (in absolute value). The equation for this relationship is shown below:

$\frac{\text { Advertising dollars }}{\text { Sales dollars }}=\frac{\varepsilon_{Q A}}{\varepsilon_{Q P}}$.

The Dorfman-Steiner theorem is static because it assumes that advertising efforts last only one time period, but it can be generalized readily to a dynamic case in which the effects of advertising efforts persist several periods into the future-the so-called carryover effects (Schmalensee 1972). When there are several marketing instruments (and constant unit marketing media costs), under reasonable conditions the optimal ratio of expenditures for any two media equals the ratio of their marketing elasticities (Palda 1969).

In terms of demand marketing elasticities and advertising-sales ratios, it is useful to consider the taxonomy of Nelson $(1970,1974)$, who has distinguished search and experience goods as polar opposites. If a consumer can determine a product's quality and impact prior to purchase merely by visual, tactile, or analytical inspection, the product is said to have search qualities. Examples of search goods are many electronic goods, tools, and credit cards. If a customer must consume the product to predict its quality and impact, the good is said to have experience qualities. Examples of experience goods include cosmetics, restaurants, and cereals. In practice precise demarcation of goods into search versus experience is not possible, particularly when multiattribute goods have both search and experience qualities. In general, however, goods with dominant experience attributes have greater advertising-sales ratios than do goods with dominant search qualities. To the extent prescription pharmaceuticals have idiosyncratic and unpredictable effects (differential efficacy, side effects, and adverse interactions with other drugs), pharmaceuticals would appear to have more experience than search qualities. For those pharmaceuticals having highly predictable outcomes, however, search qualities may dominate.

Carlton and Perloff (1994) suggest that producers of search goods are more likely to use informational advertising, while experience goods producers are more likely to use persuasive advertising. They note, however, that the division is not perfect, nor is there unanimity in what constitutes information versus persuasion. They interpret the greater 
advertising-sales ratios of experience goods as possibly reflecting the fact that "images (used in persuasive advertising) are forgotten more quickly than facts (used in informative advertising). Thus, consumers may learn and remember that a particular good has fewer calories (is "less filling") in one or a few exposures to an advertisement, but need to be bombarded with repeated exposures to be convinced that a product "tastes great."

The effects of advertising on the welfare of individuals have long been analyzed and debated. Carlton and Perloff summarize this literature by stating that "the welfare effects of advertising are complex and depend on the type of product and type of advertising," and therefore "are generally ambiguous. ${ }^{18}$ Brand loyalty, for example, may reduce price responsiveness of demand, but can also reduce consumers' search costs. ${ }^{9}$ Bagwell (2001) provides a useful collection of economics articles dealing with the theoretical foundations and empirical analyses of advertising as information versus persuasion; search versus experience; and the relationships among advertising, product quality and market structure. ${ }^{10}$

Finally, in addition to affecting demand, advertising can be used as a strategic tool to affect possible entry into a product market. Ellison and Ellison (2000) hypothesize and empirically assess branded pharmaceutical firms' advertising strategies in the context of affecting potential generic entry as the brand's patent protection expires. Their model predicts and they find empirical evidence supporting the notion that branded drugs with medium-size markets reduce their advertising intensities to a greater extent prior to patent expiration than do drugs with either very small or very large markets.

\section{The Marketing of Prescription Pharmaceuticals: Descriptive Data}

Pharmaceutical companies currently employ several promotional strategies for prescription drugs designed to target physicians and consumers, respectively (table 1.2). Because physicians have long been the key decision makers when it comes to choosing a prescription drug, pharmaceutical companies traditionally have concentrated most of their marketing efforts on physicians, and still do so today. These physicianoriented marketing efforts include visits or phone calls by pharmaceutical sales representatives to physicians (detailing), free samples, print advertising, and sponsorship of medical education events. In 2000 , the 
Table 1.2

Spending on physician-directed promotion and promotion to sales ratios, 1996-2000

\begin{tabular}{lrrrrr}
\hline Dollars (thousands) & 1996 & 1997 & 1998 & 1999 & 2000 \\
\hline Detailing & 3,010 & 3,365 & 4,057 & 4,320 & 4,803 \\
Journal advertising & 459 & 510 & 498 & 470 & 484 \\
Retail value of samples & 4,904 & 6,047 & 6,602 & 7,230 & 7,954 \\
Total physician promotion & 8,373 & 9,922 & 11,157 & 12,020 & 13,241 \\
Direct-to-consumer promotion & 791 & 1,069 & 1,317 & 1,848 & 2,467 \\
Total Promotion & 9,164 & 10,991 & 12,474 & 13,868 & 15,708 \\
\hline Promotion to sales ratios & 1996 & 1997 & 1998 & 1999 & 2000 \\
\hline Detailing & 0.046 & 0.047 & 0.050 & 0.043 & 0.043 \\
Journal advertising & 0.007 & 0.007 & 0.006 & 0.005 & 0.004 \\
Retail value of samples & 0.076 & 0.084 & 0.081 & 0.071 & 0.071 \\
Total physician promotion & 0.129 & 0.138 & 0.137 & 0.118 & 0.118 \\
Direct-to-consumer promotion & 0.012 & 0.015 & 0.016 & 0.018 & 0.022 \\
Total promotion & 0.141 & 0.153 & 0.153 & 0.136 & 0.140 \\
\hline
\end{tabular}

Sources: Physician promotion spending data are from IMS Health, Integrated Promotional Services ${ }^{\mathrm{TM}}$, June 2001; sales data are from Pharmaceutical Research and Manufacturers of America, Annual Survey, 2001; direct-to-consumer promotion spending data are from IMS Health and Competitive Media Reporting, June 2001.

vast majority of spending on physician-oriented promotion (about 81 percent) was concentrated on detailing (30.6 percent) and samples (50.6 percent).

Consumer-oriented promotion, which includes advertising in both print and electronic media, was nearly nonexistent as an approach to promotion of pharmaceuticals in the United States as of 1980. Beginning in the 1980s and early 1990s, a limited amount of DTCA began appearing. By 1994 a rapidly increasing trend in DTCA spending became apparent (figure 1.1). The release of the clarified FDA guidelines in 1997 occurred in the midst of this trend and may have accelerated it. By 2000, DTCA comprised 15.7 percent of total promotion expenditures. ${ }^{11}$

As shown in table 1.1, there is very substantial heterogeneity in DTCA and physician-oriented promotion to sales ratios. For new products, this ratio can be as high as 2.05 (Aciphex, a proton pump inhibitor), and as low as 0.0 (Mevacor, a cholesterol-reducing drug). Within classes, there is also substantial heterogeneity in DTCA, detailing, and sampling to dollar sales ratios (e.g., the antidepressants and nasal spray classes in table 1.1). 


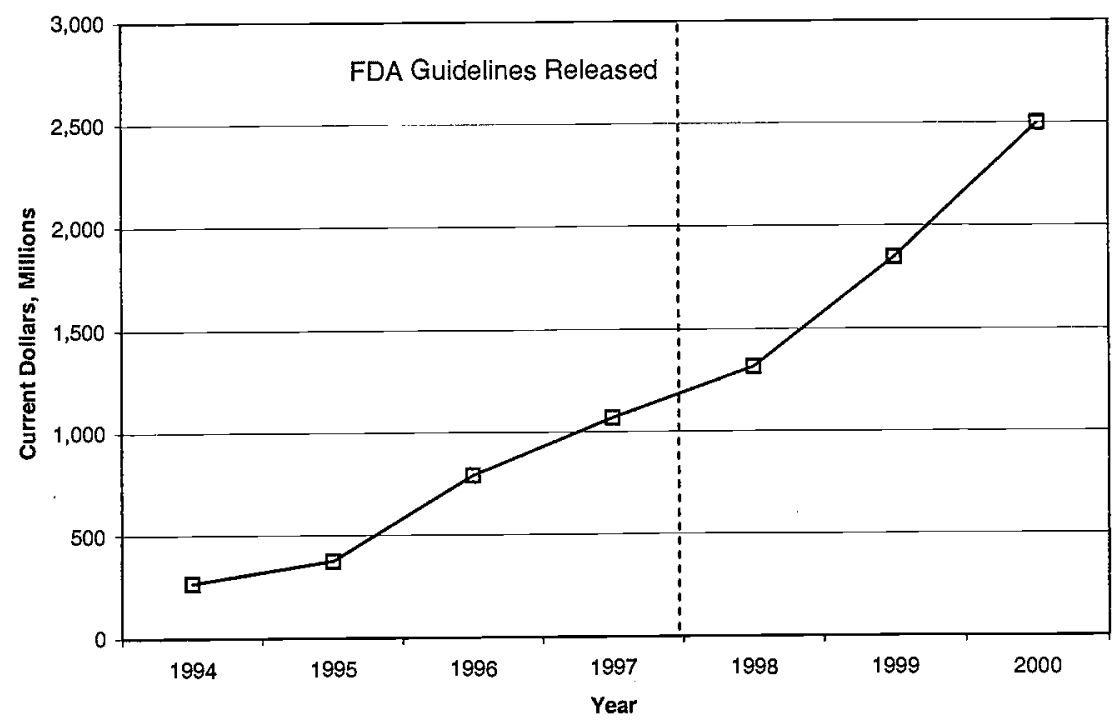

Figure 1.1

Trend in direct to consumer advertising spending, 1994-2000

Source: IMS Health and Competitive Media Reporting

\section{Empirical Implementation}

Our aim is to estimate the impact of DTCA on consumer demand for prescription drugs. The literature on the demand for prescription drugs uses several approaches to model specification, including implementation of an almost ideal demand system (AIDS), Cobb-Douglas specifications, and logit models (Ellison et al. 1997; Rizzo 1999; King 2000; Ling, Berndt, and Kyle 2002; Frank and Hartman 2002). Each specification has its advocates in the literature. None has yet been shown to be superior in estimating demand models in markets for prescription drugs.

Following others, in the demand analysis pursued here we estimate the demand for prescription drug products in the context of multistage budgeting. That is, we estimate models of the impact of promotional spending (DTCA and detailing) at the level of the entire therapeutic class (e.g., selective serotonin reuptake inhibitors [SSRI] antidepressants) and at the level of the individual product within the class (e.g., Prozac among the SSRIs). ${ }^{12}$ This multistage structure is illustrated in figure 1.2. At the top level of the tree, which represents the therapeutic 

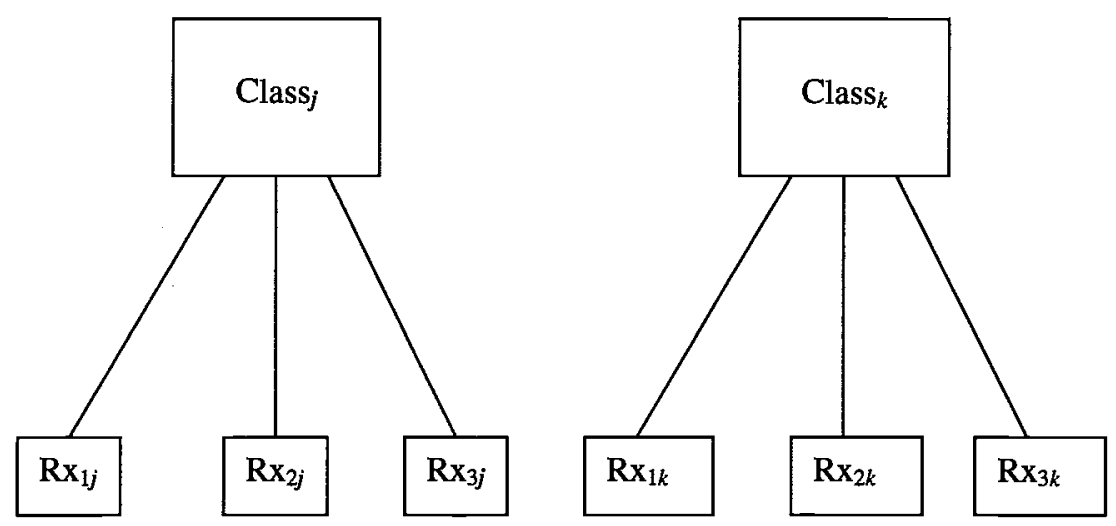

Figure 1.2

Multi-tier demand structure

class of drugs, we estimate the impact of DTCA spending and detailing in the context of a Cobb-Douglas demand specification (double logarithmic). In the analysis of competition at the individual product level within each class, we specify and estimate three alternative models: (1) an AIDS type specification; (2) a logit model with log of quantity share divided by ( 1 - quantity share) on the left-hand side, and prices and promotional spending on the right-hand side; and (3) a CobbDouglas model in log levels.

\section{Data Sources}

We examine monthly data from August 1996 to December 1999 for five therapeutic classes of drugs: recent vintage anti-depressants (SSRIs plus serotonin/norepinephrine reuptake inhibitors [SNRIs]), antihyperlipidemics, proton pump inhibitors, nasal sprays, and antihistamines (table 1.2). These classes were selected on the basis of the following criteria: (1) presence of at least one product with high DTCA expenditures during the time period, (2) within-class variation in DTCA, and (3) within-class variation in the life cycles of the drugs. The classes treat a wide variety of ailments, are indicated for different patient populations, and are prescribed by several different clinical specialties. Data were collected on all of the drugs in each of these five classes.

Sales and promotion data for the selected products were obtained from marketing research firms. Data on DTCA spending were obtained 
from Competitive Media Reporting (formerly known as Leading National Advertisers), which tracks local and national advertising campaigns in major media, such as television and radio, for brands with at least $\$ 25,000$ in annual advertising expenditures. Three major components of professional promotional spending are reported here: detailing to office-based physicians, detailing to hospital-based physicians, and the value of free samples left with physicians. Drugspecific data on professional journal advertising, which represents a small percentage of overall promotional expenditures for products in the six drug classes, was not included.

Spending data on detailing were obtained from Scott-Levin Inc., a pharmaceutical market research firm. Scott-Levin imputes spending on detailing from a panel of roughly 12,000 office- and hospital-based physicians, which comprises roughly $2-3$ percent of the U.S. physician population. The physicians track their contacts with pharmaceutical sales representatives. Data on the retail value of free samples provided by pharmaceutical companies were obtained from IMS Health, which uses a panel of 1,265 front office staff in medical practices to monitor the volume of samples dropped off by sales representatives. Sales data were obtained from Scott-Levin, which audits over 35,000 retail pharmacies and projects total sales based on an independent estimate of total U.S. retail sales of prescription drugs.

Market shares were constructed from product-level data on sales for the drugs in each of the five classes. Price data were constructed by Scott-Levin using their sales data. We then created a quantity sold variable based on dividing sales by price for a particular month. Note that this price variable is not the average consumer copayment for that drug, but instead is the average price received by wholesalers from their customers.

Patent information was collected from the Food and Drug Administration's Orange Book. A variable was created to indicate the number of months left on a product's patent. Order of entry within a class was determined based on the FDA approval date available through the Orange Book.

Table 1.2 identifies the therapeutic class and individual product combinations that are analyzed below. Together these five classes accounted for 30 percent of all DTCA in 1999. Table 1.2 also reports the year each drug was approved, the three-year average promotion to sales ratio for detailing, sampling, and DTCA. 


\section{Basic Models}

We now set out the basic estimation models used in the analysis. As noted above, the Cobb-Douglas formulation is used for both the class level demand model as well as the individual product demand model. Equation (1.2) is the Cobb-Douglas specification for the product specific analyses:

$\ln q=\alpha+\beta_{1} \ln \mathrm{DTCA}+\beta_{2} \ln$ Det $+\sum_{j} \delta_{j} X_{j}$

where Det is detailing and the $X_{j}$ are other explanatory variables.

Equation (1.3) represents the general specification of the modified AIDS model.

$S_{i}=\alpha+\beta_{i} \ln \left(\frac{P_{i}}{P_{i}}\right)+\phi_{i} \ln \mathrm{DTCA}+\phi_{2} \ln$ Det $+\sum_{i x} \sigma_{i x} X_{i x}$

where $S_{i}$ is the dollar revenue share of the $i$ th drug within a therapeutic class, and $P_{i}$ and $P_{j}$ are prices of drugs $i$ and $j$ (in our model, $P_{j}$ is actually the share-weighted price index for other competitors in the class, since there are more than two drugs in every class). Finally, we use the same regressors in estimating model specifications where the dependent variable is specified as the logit of quantity shares for the individual drug products. Several variants of these specifications are also estimated, as discussed below.

Specification and Measurement of Key Variables

There are two important sets of measurement and specification issues with our demand models of prescription drug promotion: (1) the measurement and specification of the price variables, and (2) the specification of promotional spending. The appropriate price to measure in a traditional consumer demand model is the out-of-pocket cost of the drug to the consumer. For various reasons, this desired measure is not available. The Scott-Levin data we analyze measure price as the payment made by drugstores to wholesalers for each drug. Because this measure takes into account discounts and charge-backs to pharmaceutical manufacturers, these prices are not simple list prices. Nevertheless, these observed prices do not account for the rebates given to health plans and other third-party payers for prescription drugs, nor the structure of beneficiary cost sharing for prescription drugs by health 
plans. Both the level of rebates obtained by different payers and the structure of copayments are quite heterogeneous, even within the customers of a single drugstore (Frank 2001). Thus, the observed prices are measured with error and are probably not closely correlated with the desired consumer out-of-pocket price. For these reasons, we take two approaches in empirical implementation. In one set of models, we include the mismeasured price variables. In another set of models, we omit the price variables and instead include a more extensive set of indicator variables to account for time trends and unobserved crosssectional effects.

The specification of measures of promotional spending has generally taken one of three forms in the literature. Promotion has been treated as a simple flow variable that is measured by current levels of promotional spending (Wosinska 2001). That approach assumes that current buying behavior depends largely on current exposure to promotional activities. A second approach specifies promotional activity as affecting consumer choice in terms of a lag structure (Rizzo 1999, Wosinska 2001). The assumption here is that the appropriate measure is still viewed as a flow, only there is a lagged response to the promotional activities. The third approach is to treat promotional activity as a stock that depreciates at a constant rate over time (Berndt et al. 1995, 1997).

Our point of departure is to treat promotional spending as a simple flow. We also explored creating a stock. Our historical data on DTCA and detailing is quite limited, however. Therefore, we experimented with a variable based on three-month cumulative spending. When we used this variable in the specifications, our time series was shortened, and the resulting parameter estimates did not differ markedly from those assuming a simple flow. Therefore, we chose to focus on the results that are based on treating promotional spending as a simple flow.

We account for the possibility that spending on DTCA and physician promotion and product sales are jointly determined by estimating instrumental variables (IV) models where all three variables are assumed to be endogenous. Three sets of variables serve as the basis for our exclusion restrictions in the IV specifications for the product specific demand equations. The first is the time left on the patent for each drug (and its square). This is based on the notion that for products reaching the end of their patent protection period, there is little incentive to invest in promotion (Frank and Salkever 1992; Berndt, Kyle, and Ling 2002). The length of the patent life remaining is determined far in advance of current sales decisions, and there is no direct effect on sales 
because there is no generic competition yet in place for these drugs. The second instrument reflects the timing of the FDA's clarification of the conditions governing direct to consumer advertising on television (and the interaction of that indicator with time). In 1997 the FDA clarified that television advertisements could refer consumers to a physician, a 1-800 number, a manufacturer's web site, and a magazine article that provides the full description of the drugs as required by labeling regulations. This clarification served to reduce the cost of airing a television promotional spot but should not have had a direct impact on sales. The third instrument is the interpolated monthly value of television advertising costs per minute, based on annual data from Robert M. Coen Associates.

The IV model for DTCA is estimated using a two-part model. The first stage is a logit of whether there was any spending on DTCA in a given month, and the second stage is a regression model on the natural $\log$ of DTCA conditional on any spending (Cragg 1971, Duan et al. 1983). For detailing, a simple two-stage IV was estimated because all drugs in the sample were promoted via detailing.

Finally, we experiment with several specifications of a time effect. We use a combination of quarterly dummy variables to capture seasonal effects, and a quadratic time trend to account for secular trends in the pharmaceutical marketplace. All models estimate standard errors robust to heteroskedasticity and clustering.

\section{Econometric Results}

We begin by presenting results in table 1.3 for the top of the tree structure in figure 1.2, the class level quantity equations. Three specifications of the Cobb-Douglas functional form are reported. They differ according to whether a monthly time trend was included in the model (only in column 3) and whether interaction effects between drug class and quarter were included (only in column 3). Overall, the models fit the data well with $R^{2}$ statistics of 0.60 to 0.95 .

The estimated elasticities of DTCA and detailing are quite stable across model specifications. For spending on DTCA, the estimated elasticity ranges from 0.096 to 0.114 . All estimates are very precise, with $t$-statistics of about 10 . The results suggest that a 10 percent increase in DTCA spending would result in approximately a 1 percent increase in sales, other things being equal. 
Table 1.3

Drug class demand models

\begin{tabular}{|c|c|c|c|}
\hline & \multicolumn{3}{|c|}{ Dependent variable $^{a}$} \\
\hline & $\ln Q$ & $\ln Q$ & $\ln Q$ \\
\hline \multirow[t]{2}{*}{ Class DTC } & 0.114 & 0.099 & 0.096 \\
\hline & $(0.01)$ & $(0.01)$ & $(0.009)$ \\
\hline \multirow[t]{2}{*}{ Class detail $^{\mathrm{b}}$} & 0.017 & 0.034 & 0.031 \\
\hline & $(0.004)$ & $(0.003)$ & $(0.003)$ \\
\hline Quarter dummies & Included & Included & Included \\
\hline Class dummies & Included & No & No \\
\hline Interaction & Included & No & No \\
\hline Month & No & No & Included \\
\hline Month $^{2}$ & No & No & Included \\
\hline \multirow[t]{2}{*}{ Constant } & 10.02 & 9.92 & 9.89 \\
\hline & $(0.18)$ & $(0.19)$ & $(0.20)$ \\
\hline$R^{2}$ & 0.95 & 0.60 & 0.62 \\
\hline Equation $F$ & 280.0 & 56.0 & 48.87 \\
\hline
\end{tabular}

${ }^{a}$ Robust SE in parentheses.

bEndogenous, IV estimated.

The case of proton pump inhibitors (PPIs) offers insights into the implications of this result. Between 1998 and 1999, PPI class sales grew from $\$ 4.2$ billion to $\$ 5.7$ billion, a change of nearly 36 percent. During the same period, DTCA spending for PPI products grew from $\$ 49.7$ million to $\$ 80.1$ million, an increase of 60 percent. Using an elasticity of 0.10 (based on the results reported above) suggests that about 6 percentage points of the growth in PPI spending is directly attributable to DTCA. That translates into $\$ 252$ million in sales, or about 17 percent of the sales increase from 1998 to 1999. Note that the increase in PPI sales directly attributable to increased DTCA is about 8.3 times the increase in DTCA ( $\$ 252$ versus $\$ 30.4$ million).

For the case of nasal sprays, DTCA spending grew by 37 percent between 1998 and 1999 (from $\$ 83$ to $\$ 115.2$ million). The corresponding growth in sales was from $\$ 726$ million to $\$ 990$ million, or 36 percent. The elasticity estimate suggests that the growth in DTCA spending was responsible for a 3.7 percent growth in sales, or 10.3 percent of the total growth in sales. That amounts to about $\$ 26$ million. Here the sales increase directly attributable to increased DTCA spending is only 0.8 times the DTCA increase ( $\$ 26$ versus $\$ 32.2$ million). Industry officials have suggested to us that their targeted changes in sales are in the range of 
four to five times the change in DTCA spending at the brand level (increased sales are also associated with increased production costs, sales commissions, licensing fees, and general administrative costs).

The coefficient estimates for the impact of detailing on sales imply elasticity estimates between 0.017 and 0.034 . Again all three estimates are estimated quite precisely with $t$-statistics ranging from 4.25 to about 10. Because changes in detailing were on the order of 7 to 15 percent in the late 1990s and early 2000s, the impact of growth in detailing on class sales is considerably smaller than it was for drugs using DTCA as a key promotional strategy. Thus, at the entire class level, for these therapeutic classes DTCA has a larger marketing elasticity than does detailing.

Tables 1.4 and 1.5 present the product-specific demand models. All product-specific models include class fixed effects. Table 1.4 presents

Table 1.4

Individual product demand models with prices ${ }^{\mathrm{a}}$

\begin{tabular}{|c|c|c|c|}
\hline & \multicolumn{3}{|c|}{ Dependent variable } \\
\hline & Dollar share & $\ln [(Q$ share $) /(1-Q$ share $)]$ & $\ln Q$ \\
\hline \multirow[t]{2}{*}{ Constant } & -0.281 & -9.971 & 1.544 \\
\hline & $(0.88)$ & $(4.66)$ & $(4.23)$ \\
\hline \multirow[t]{2}{*}{$\ln \mathrm{DTCA}^{\mathrm{b}}$} & 0.025 & 0.091 & 0.071 \\
\hline & $(0.03)$ & $(0.11)$ & $(0.11)$ \\
\hline \multirow[t]{2}{*}{$\ln \operatorname{Det}^{b}$} & 0.004 & 0.690 & 0.730 \\
\hline & $(0.14)$ & $(0.698)$ & $(0.63)$ \\
\hline \multirow[t]{2}{*}{ Order entry } & 0.127 & 0.619 & 0.615 \\
\hline & $(0.69)$ & $(0.49)$ & $(0.49)$ \\
\hline \multirow[t]{2}{*}{$(\text { Order entry })^{2}$} & -0.017 & -0.087 & -0.089 \\
\hline & $(0.009)$ & $(0.09)$ & $(0.09)$ \\
\hline \multirow[t]{2}{*}{$\ln \left(P_{i} / P_{\text {others }}\right)$} & 0.129 & 1.120 & 1.108 \\
\hline & $(0.07)$ & $(0.41)$ & $(0.39)$ \\
\hline Class dummies & Included & Included & Included \\
\hline \multirow[t]{2}{*}{ Month } & -0.0004 & -0.171 & 0.042 \\
\hline & $(0.03)$ & $(0.01)$ & $(0.02)$ \\
\hline \multirow[t]{2}{*}{ Month ${ }^{2}$} & 0.720 & 0.0022 & -0.0007 \\
\hline & $(0.88)$ & $(0.0003)$ & $(0.0004)$ \\
\hline$R^{2}$ & 0.54 & 0.65 & 0.69 \\
\hline Equation $F$ & 16.51 & 54.99 & 34.97 \\
\hline
\end{tabular}

${ }^{a}$ Robust SE in parentheses.

${ }^{b}$ Endogenous, IV estimated. 
Table 1.5

Individual product demand models with price excluded as regressor ${ }^{\mathrm{a}}$

\begin{tabular}{|c|c|c|c|}
\hline & \multicolumn{3}{|c|}{ Dependent variable } \\
\hline & Dollar Share & $\ln [(Q$ share $) /(1-Q$ share $)]$ & $\ln Q$ \\
\hline \multirow[t]{2}{*}{ Constant } & 1.746 & -9.771 & 4.413 \\
\hline & (1.29) & $(10.58)$ & $(10.79)$ \\
\hline \multirow[t]{2}{*}{$\ln \mathrm{DTCA}^{\mathrm{b}}$} & 0.077 & 0.167 & 0.216 \\
\hline & $(0.04)$ & $(0.23)$ & $(0.24)$ \\
\hline \multirow[t]{2}{*}{$\ln \operatorname{Det}^{b}$} & -0.254 & 0.77 & 0.443 \\
\hline & $(0.18)$ & (1.43) & (1.46) \\
\hline \multirow[t]{2}{*}{ Order entry } & 0.100 & 0.269 & 0.313 \\
\hline & $(0.06)$ & $(0.62)$ & $(0.61)$ \\
\hline \multirow[t]{2}{*}{$(\text { Order entry })^{2}$} & -0.011 & -0.067 & -0.071 \\
\hline & $(0.01)$ & $(0.10)$ & $(0.10)$ \\
\hline Class dummies & Included & Included & Included \\
\hline Quarter dummies & Included & Included & Included \\
\hline Interaction & Included & Included & Included \\
\hline \multirow[t]{2}{*}{ Month } & -0.007 & -0.181 & 0.026 \\
\hline & $(0.004)$ & $(0.04)$ & $(0.03)$ \\
\hline \multirow[t]{2}{*}{ Month $^{2}$} & 0.0001 & 0.002 & -0.0003 \\
\hline & $(0.0001)$ & $(0.0009)$ & $(0.001)$ \\
\hline$R^{2}$ & 0.37 & 0.47 & 0.52 \\
\hline Equation $F$ & 24.42 & 51.86 & 17.96 \\
\hline
\end{tabular}

${ }^{a}$ Robust SE in parentheses.

${ }^{\mathrm{b}}$ Endogenous, IV estimated.

results for models where a relative price measure is included as a rightside regressor. Table 1.5 omits the relative price measure and instead includes quarterly dummy variables and interactions between quarter and class. The quarters are meant to account for seasonal effects and the fact that these might vary for different classes (antihistamines versus antidepressants). All six sets of estimates presented treat detailing and DTCA as endogenous. (One finding worthy of note in the first-stage regressions is that the impact of the 1997 FDA clarification on regulations governing DTCA had no significant effect on DTCA spending levels.)

IV estimates of the coefficient on the price variable in table 1.4 are positive, significant in two of the three models, and of the wrong sign. As noted earlier, we believe the price variable is measured with error, and has no close relationship to patient copayments. 
The various models in tables 1.4 and 1.5 yield relatively consistent findings with respect to the estimates for the effect of DTCA and detailing on individual product sales. The coefficient estimates for the log of DTCA are consistently positive and estimated imprecisely. In five of six specifications, the standard errors are larger than the estimated coefficient. In the first column of table 1.5 , the estimated coefficient has a $t$-statistic of 1.92 that is not quite significantly different from zero at conventional levels. The estimated DTCA elasticities are not consistent in magnitude across the estimated models, nor in levels versus shares. To the extent DTCA affects class sales, one would expect a larger level elasticity (column 3) than a share elasticity (columns 1 and 2). This is not always the case. However, the Cobb-Douglas model in table 1.5 yields an elasticity of about 0.22 , larger than the share elasticity.

The results for the impact of detailing on sales for individual drugs show coefficient estimates that are typically positive and imprecisely estimated. The first column of table 1.5 reports a negative coefficient estimate for the log of detailing variable, but this coefficient is not significantly different from zero at conventional levels. Although the detailing elasticity estimates are all larger than those for DTCA, the detailing elasticity estimates never approach statistical significance.

Order of entry and its square were never found to be significantly different from zero in any of the estimated models. The magnitudes of the DTCA and detailing coefficients in the product-level models are quite sensitive to the form of the dependent variable and to the manner in which time dummies are specified. Finally, we also estimated a variant of the Cobb-Douglas model where both own DTCA and competitor DTCA levels were specified as right-side variables. The results were not materially different from those reported in tables 1.4 and 1.5. The time trend results for the share regressions reflect therapeutic competition because they tend to be negative for most of the observed period as the number of competitors increases. The quantity regression reflects the growth in the class over time and this is a generally positive time trend.

\section{Comments on Results}

The DTCA parameter estimates we obtained at the entire therapeutic class level are both quite robust and relatively precisely estimated. Estimates of the detailing elasticities at the entire therapeutic class level 
are also positive and significant, generally smaller than the DTCA elasticities, and not quite as robust. In contrast, both DTCA and detailing parameter estimates for the individual product demand models are neither robust nor precisely estimated.

Nonetheless, we believe it is premature to conclude that DTCA affects only class level sales and not individual product sales. The stability of both DTCA and detailing spending is far greater at the class level than at the individual product level, and thus the product level demand models may not be capturing properly the complex timing relationships between marketing efforts and measured sales, particularly since the latter involve sales to drugstores, not from drugstores to patients. However, the three-month cumulative log formulation gave similar results, even though it was less volatile than the current flow measure. The greater stability at the class level gives us some confidence in the class level results.

One potential reason for the instability of results at the product level is the experimentation with DTCA. One implication is that such trialand-error spending might wash out the product-level effects but not the class-level effects. Thus, spending on DTCA may fail to increase one's own demand, but still increase class demand. We view the question of the impact of DTCA spending at the individual product level as still remaining quite uncertain, a topic that merits additional research. If our class and product share results stand up after additional research, they could have an interesting implication. Specifically, these findings are consistent with the notion that DTCA brings previously untreated patients into physicians' offices where they receive a prescription for a product in the advertised class of drugs. How physicians balance their own product preferences and those of consumers is less certain. Thus, DTCA might positively affect class sales, but possibly not within-class product shares. Whether such additional prescribing at the class level is medically appropriate (a key question for public health) is, of course, beyond the scope of the present analysis.

This interpretation of our DTCA findings is consistent with the microeconomic evidence reported by Wosinska (2001) for cholesterolreducing medications. She finds that DTCA, unlike detailing, affects individual drug market share only if that brand happens to have preferred status on the third-party payer's formulary. It is also consistent with evidence from Ling, Berndt, and Kyle (2002), who find that, for 
the $\mathrm{H}_{2}$-antagonists, there is no significant spillover impact on samebrand Rx market share, nor does DTCA on the Rx brand affect Rx market share, although DTCA on over-the-counter (OTC) brands has a positive impact on own-brand OTC market share.

Finally, we considered the overall impact on prescription drug spending of the growth in DTCA. We examined 1999 and 2000 DTCA spending and sales for the 25 largest therapeutic classes, which account for about 70 percent of total prescription drug spending. We applied our 0.10 elasticity only to those classes with DTCA activity but aggregated the effects in two ways. First, we applied the elasticity class by class and totaled the class-level effects. Because there were some cases where DTCA growth resulted in estimates out of range (we overpredicted sales growth) as well as some instances of DTCA spending declines, we also applied our average elasticity to total DTCA spending growth for those classes that advertise and multiplied this figure by 1999 sales for those classes. The absolute change in sales attributable to DTCA was then compared to the total growth in prescription drug sales. The two different aggregation approaches yielded estimates of DTCA-attributable spending growth of 22 percent and 13 percent, respectively, of total prescription drug spending growth. Thus, our estimates indicate that DTCA is important, but is not the primary driver of recent growth.

\section{Notes}

Financial support from the Henry J. Kaiser Family Foundation is gratefully acknowIedged. We are also grateful to Alan Garber, Joseph Newhouse, Ariel Pakes, Alvin Silk, and participants in the NBER Health Care Economics Program Meeting for helpful suggestions.

1. These quotes are from Carlton and Perloff (1994), p. 604.

2. As quoted in the Boston Globe (Mishra 2002). Words in brackets added for clarification.

3. However, DTCA dominated drug advertising prior to the 1938 FDA prescription-only legislation and the 1951 Humphrey-Durham Amendment to the Federal Food, Drug and Cosmetic Act that established physicians as "learned intermediaries" and made many drugs available only with a physician's prescription. Temin (1980, pp. 82-87) estimates that in 1930, 90 percent of drug advertising expenditures occurred in newspapers and popular magazines; only 2 percent in technical journals; and only 3 percent involved detailing, samples, and other.

4. For an historical account of DTCA controversies, see Masson (1991).

5. See also Ziegler, Lew, and Singer (1995). 
6. Twenty-five years of experience in modeling the impact of detailing on sales, and on optimizing sales force size and targets, is summarized in Sinha and Zoltners (2001). A classic study of detailing is written by Lodish et al. (1988).

7. Carlton and Perloff (1994), p. 603.

8. Carlton and Perloff (1994), p. 625.

9. For empirical evidence on consumers' search costs for acute versus chronic medications, and impact on retail pricing of drugs, see Sorenson (2000).

10. See also Scherer (2000).

11. Industry officials tell us that absolute levels of DTCA spending are likely to be overstated because Competitive Media Reporting estimates DTCA spending using "list" rather than actual transaction prices. Because of the large amount of advertising services pharmaceutical firms purchase, they typically obtain substantial discounts off list prices. These industry officials suggest that the DTCA estimates by Competitive Media Reporting are reasonably reliable estimates of relative DTCA across drugs.

12. We also estimate a variant of the strict two-stage budgeting model where we allow both class level DTCA and own DTCA to affect the demand for a particular drug.

\section{References}

Aikin, Kathryn J. (April 18, 2002). "Direct-to-Consumer Advertising of Prescription Drugs: Preliminary Patient Survey Results." PowerPoint presentation given at Second Annual DTC National Conference and Exposition, Boston, Mass.

Alperstein, N., and M. Peyrot (July / August 1993). "Consumer Awareness of Prescription Drug Advertising," Joumal of Advertising Research, 33(4):50-56.

Avorn, Jerry, Milton Chen, and Robert Hartley (July 1982). "Scientific Versus Commercial Sources of Influence on the Prescribing Behavior of Physicians," The American Journal of Medicine, 73:4-8.

Bagwell, Kyle, ed. (2001). The Economics of Advertising, The International Library of Critical Writings in Economics, Vol. 136, Cheltenham, UK: Edward Elgar Publishing Ltd.

Bain, Joe S. (1956). Barriers to New Competition, Cambridge, Mass.: Harvard University Press.

Berndt, Ernst R., Linda T. Bui, David H. Reiley, and Glen L. Urban (May 1995). "Information, Marketing and Pricing in the U.S. Anti-Ulcer Drug Market," American Economic Review, 85(2):100-105.

Berndt, Ernst R., Linda T. Bui, David H. Reiley, and Glen L. Urban (1997). "The Roles of Marketing, Product Quality and Price Competition in the Growth and Composition of the U.S. Anti-Ulcer Drug Industry," Chapter 7 in Timothy F. Bresnahan and Robert J. Gordon, eds., The Economics of New Products, Studies in Income and Wealth, Volume 58, Chicago, Jll.: University of Chicago Press for the National Bureau of Economic Research, 277-322.

Berndt, Ernst R., Margaret Kyle, and Davina Ling (2002). "The Long Shadow of Patent Expiration: Generic Entry and Rx to OTC Switches," MIT Program on the Pharmaceutical Industry, September 2000. Revised January 2002. Forthcoming in Robert C. Feenstra and 
Matthew D. Shapiro, eds., Scanner Data and Price Indexes, NBER Series on the Conference on Research in Income and Wealth, Chicago, Ill.: University of Chicago Press for the National Bureau of Economic Research.

Bond, Ronald S., and David F. Lean (February 1997). Sales, Promotion and Product Differentiation in Two Prescription Drug Markets, Washington, D.C.: Staff Report of the Bureau of Economics of the Federal Trade Commission.

Borzo, G. (February 10, 1997). "Consumer Drug Ads Booming: FDA Reviews Restrictions," American Medical News, 40(6):1, 37.

Carlton, Dennis W., and Jeffrey M. Perloff (1994). Modern Industrial Organization, 2nd edition, New York: HarperCollins College Publishers.

Cragg, John G. (September 1971). "Some Statistical Models for Limited Dependent Variables with Application to the Demand for Durable Goods," Econometrica, 39(5):829-844.

Dorfman, Robert, and Peter O. Steiner (December 1954). "Optimal Advertising and Optimal Quality," American Economic Review, 44(5):826-836.

Duan, Naihua, Willard G. Manning, Jr., Carl N. Norris, and Joseph P. Newhouse (April 1983). "A Comparison of Alternative Models for the Demand for Medical Care," Journal of Business and Economic Statistics, 1(2):115-126.

Ellison, Glenn, and Sara Fisher Ellison (2002). "Strategic Entry Deterrence and the Behavior of Pharmaceutical Incumbents Prior to Patent Expiration," unpublished manuscript, Cambridge, Mass.: Massachusetts Institute of Technology, Department of Economics. Downloaded from web.mit.edu/gellison/www/drugs20.pdf.

Ellison, Sara Fisher, Iain Cockburn, Zvi Griliches, and Jerry Hausman (Autumn 1997). "Characteristics of Demand for Pharmaceutical Products: An Examination of Four Cephalosporins," RAND Journal of Economics, 28(3):446-466.

Frank, Richard G. (March/April 2001). "Prescription Drug Prices: Why Do Some Pay More Than Others Do?" Health Affairs, 20(2):115-128.

Frank, Richard G., and David S. Salkever (October 1992). "Pricing, Patent Loss, and the Market for Pharmaceuticals," Southern Economic Journal, 59(2):165-179.

Frank, Richard G., and Raymond S. Hartman (April 2002). "Competition Between Brands and Generic Drugs and the Merger Guidelines," Boston, Mass.: Harvard Medical School working paper.

Gonul, Fusun, Franklin Carter, Elina Petrova, and Kannan Srinivasan (2001). "Promotion of Prescription Drugs and Its Impact on Physician Choice Behavior," Journal of Marketing, 65(3):79-90.

Gonul, Fusun, Franklin Carter, and Jerry Wind (2000). "What Kind of Patients and Physicians Value Direct-to-Consumer Advertising of Prescription Drugs," Health Care Management Science, 3:215-226.

Grossman, Gene M., and Carl Shapiro (January 1984). "Informative Advertising with Differentiated Products," Review of Economic Studies, 51(1):63-81.

Hurwitz, Mark A., and Richard E. Caves (October 1988). "Persuasion or Information? Promotion and the Shares of Brand Name and Generic Pharmaceuticals," Journal of Law and Economics, 31(5):299-320. 
Kaldor, Nicholas (1950). "The Economic Aspects of Advertising," Review of Economic Studies, 18:1-27.

Kaufman-Sherr, M., and D. Hoffman (October 1997). "Physicians-Gatekeepers to DTC Success," Pharmaceutical Executive, 17(10):56.

King, Charles III (2000). "Marketing, Product Differentiation and Competition in the Market for Antiulcer Drugs," Boston, Mass.: Harvard Business School working paper No. 01-014.

Kreling, David H., David A. Mott, Joseph B. Wiederholt, Janet Lundy, and Larry Levitt (July 2000). Prescription Drug Trends: A Chartbook, Menlo Park, Calif.: Henry J. Kaiser Family Foundation.

Leffler, Keith B. (April 1981). "Promotion or Information? The Economics of Prescription Drug Advertising," Journal of Law and Economics, 24(2):45-74.

Ling, Davina, C. Y., Ernst, R. Berndt, and Margaret K. Kyle (March 2002). "Deregulating Direct to Consumer Marketing of Drugs: Effects on Prescription and Over-the-Counter Product Sales," paper presented at the University of Chicago Law School-Medical School Conference, The Regulation of Medical Innovation and Pharmaceutical Markets, Chicago, IIl., April 20-21, 2001. Revised version, March 2002.

Lodish, Leonard M., Ellen Curtis, Michael Ness, and M. Kerry Simpson (January-February 1988). "Sales Force Sizing and Deployment Using a Decision Calculus Model at Syntex Laboratories," Interfaces, 18(1):5-20.

Manchanda, Puneet, Pradeep Chintagunta, and Susan Gertzis (May 2000). "Responsiveness of Physician Prescription Behavior to Salesforce Effort: An Individual Level Analysis," Chicago, Ill.: University of Chicago, Graduate School of Business, unpublished manuscript. Downloaded from puneet.manchanda@gsb.uchicago.edu.

Masson, Alison (199). "Direct-to-Consumer Advertising: A Continuing Controversy," in Robert N. Mayer, ed., Enhancing Consumer Choice, Proceedings of the Second International Conference on Research in the Consumer Interest, Columbia, Mo.: American Council on Consumer Interests, 159-168.

Mishra, Raja (April 17, 2002). "Ex-FDA Chief Recants on Drug Advertising," Boston Globe, A2.

Nelson, Phillip K. (March / April 1970). "Information and Consumer Behavior," Journal of Political Economy, 78(2):311-329.

Nelson, Phillip K. (July/August 1974). "Advertising as Information," Journal of Political Economy, 82(4):729-754.

Neslin, Scott (May 22, 2001). ROI Analysis of Pharmaceutical Promotion: An Independent Study. Hanover N.H.: Dartmouth College, Amos Tuck School of Business, unpublished PowerPoint presentation.

Newshour with Jim Lehrer / Henry J. Kaiser Family Foundation/Harvard School of Public Health Survey (September 2000).

Palda, Kristian (1969). Economic Analysis for Marketing Decisions, New York: Prentice-Hall.

Prevention Magazine (2001). "International Survey on Wellness and Consumer Reaction to DTC Advertising of Prescription Drugs," Vol. 1, 2000/2001, Emmaus, Pa.: Rodale. 
Rizzo, John A. (1999). "Advertising and Competition in the Ethical Pharmaceutical Industry: The Case of Antihypertensive Drugs," Journal of Law and Economics, 42(1):89-116.

Rosenthal, Meredith B., Ernst R. Berndt, Julie M. Donohue, Richard G. Frank, and Arnold M. Epstein (February 14, 2002). "Promotion of Prescription Drugs to Consumers," New England Journal of Medicine, 346(7):498-505.

Scherer, F. Michael (2000). "The Pharmaceutical Industry," Chapter x in Anthony J. Culyer and Joseph P. Newhouse, eds., Handbook of Health Economics, Amsterdam: Elsevier Publishers, Vol. 1B, 1297-1336.

Schmalensee, Richard (1972). The Economics of Advertising, Amsterdam: North-Holland.

Sinha, Prabhakant, and Andris A. Zoltners (May-June 2001). "Sales-Force Decision Models: Insights from 25 Years of Implementation," Part 2 of 2, Interfaces, 31(3):S8-S44.

Sorenson, Alan T. (August 2000). "Equilibrium Price Dispersion in Retail Markets for Prescription Drugs," Joumal of Political Economy, 4(108):833-850.

Stigler, George J. (June 1961). "The Economics of Information," Journal of Political Economy, 69(3):213-225.

Temin, Peter (1980). Taking Your Medicine: Drug Regulation in the United States, Cambridge, Mass.: Harvard University Press.

Vernon, John (1981). "Concentration, Promotion, and Market Share Stability in the Pharmaceutical Industry," Journal of Industrial Economics, 19(3):246-266.

Wosinska, Marta (October 2001). "Promoting to Multiple Agents: The Case of Direct-toConsumer Drug Advertising," Chapter 1 in unpublished Ph.D. dissertation, Berkeley, Calif:: University of California-Berkeley, Department of Economics. Downloaded from wosinska@econ.berkeley.edu.

Ziegler, M. G., P. Lew, and B. C. Singer (1995). "The Accuracy of Drug Information from Pharmaceutical Sales Representatives," Journal of the American Medical Association, 273: 1296-1298. 